\title{
Cardiovascular Risk Factors in South-Eastern Nigeria: A Community Based Survey
}

\author{
Chukwuemeka O. Eze*, Uma A. Kalu, Thomas Nnaji \\ Internal Medicine Department, Alex Ekwueme Federal University Teaching Hospital Abakaliki (AEFUTHA) Ebonyi State, Nigeria \\ Email: *drezeconauth@yahoo.com, *drezeconauth@gmail.com
}

How to cite this paper: Eze, C.O., Kalu, U.A. and Nnaji, T. (2020) Cardiovascular Risk Factors in South-Eastern Nigeria: A Community Based Survey. World Journal of Cardiovascular Diseases, 10, 417-424. https://doi.org/10.4236/wjcd.2020.107040

Received: May 12, 2020

Accepted: July 11, 2020

Published: July 14, 2020

Copyright (อ 2020 by author(s) and Scientific Research Publishing Inc. This work is licensed under the Creative Commons Attribution International License (CC BY 4.0).

http://creativecommons.org/licenses/by/4.0/ (c) (i) Open Access

\begin{abstract}
Background: Cardiovascular risk factors play a major role in cardiovascular disease burden worldwide. The prevalence is known to be in the increase especially in the developing countries. There is need for timely community based studies in order to keep tab with the current scope. It is against this background that we embarked on this cross-sectional community based study of the prevalence of selected cardiovascular risk factors in semi-urban community in Abakaliki Southeastern part of Nigeria in October 2016. Method: The consecutive consenting persons of 18 years and above were screened for selected cardiovascular risk factors in October 2016. Results: A total of 1074 adults were seen (males-567, females-507) with age range of 18 - 80 years and mean age of $35.63 \pm 12.45$ years. They were predominantly farmers, petty traders and artisans. The identified CVD risk factors were hypertension 285 (26.4\%), alcohol abuse 131 (12.1\%), obesity 122 (11.3\%), diabetes 97 (9\%), family history of stroke 87 (8.1\%), smoking $74(6.9 \%)$ and previous stroke 29 (2.7\%). Conclusion: The cardiovascular risk factors were quite prevalent with male preponderance of alcohol abuse and smoking.
\end{abstract}

\section{Keywords}

Cardiovascular, Risk Factors, Community Based Study, South-Eastern Nigeria

\section{Introduction}

Cardiovascular diseases (CVDs) are the leading cause of mortality globally [1]. It is estimated that CVDs accounted for 17.7 million human deaths in 2015 (which represents $31 \%$ of all global deaths) [2]. It is also noted that more than $75 \%$ of deaths from CVDs take place in low- and middle-income countries [2].

Cardiovascular disease risk factors are the characteristics, both modifiable and 
non-modifiable, that increase the risk of developing CVDs, and their prevalence is on the increase in the developing nations of the world [3] [4] [5]. Some of the risk factors like Hypertension, Obesity, diabetes mellitus, dyslipidemia, and smoking contribute individually and collectively to an increased risk of CVDs [6] [7].

A study in the USA amongst population of diverse backgrounds in 2012 reported prevalence of major CVDs risk factors as hypertension $25.4 \%$, obesity $36.5 \%$, diabetes $16.7 \%$, smoking $25.7 \%$ and dyslipidemia $51.7 \%$ [8].

In Nigeria, studies in Aba south-eastern and Ota southwestern Nigeria reported high prevalence of CVD risk factors in 2013 [9] [10]. Ulasi et al. in Enugu reported prevalence of hypertension amongst market workers as $42 \%$ in 2011 [11]. Eze et al. reported that stroke and heart failure constituted $24.4 \%$ and $14.7 \%$ cause of mortality in medical emergency room respectively [12]. The above studies show that the prevalence, morbidity and mortality of CVDs and their risk factors are high. There is need for regular community based studies in order to keep abreast of the current burden of CVD risk factors.

This study is set to determine the prevalence of selected CVD risk factors in a semi-urban community in Abakaliki South-eastern Nigeria.

\section{Methodology}

This was a descriptive cross-sectional study conducted in Nkaliki Unuhu, a semi-urban community in Abakaliki South-Eastern Nigeria with a population of 198,100 in 2016 according to the Nigerian National Population Census. The predominant ethnic group in this community is Igbo and majority of them are farmers. The study was conducted in October 2016 as part of activities of World stroke day celebration. Prior to the study, the adult population of the community were invited for a medical screening at a community primary school through radio jingles and town criers after approval from the community leaders. An Informed consent was obtained from the participants after detailed description of the purpose of the study. An investigator designed and pretested semi-structured questionnaire was used to obtain information on biodata, history of CVD risk factors and they were screened for selected CVD risk factors (Blood pressure, obesity, diabetes). A total of 1074 adults were screened during the study period of two days, $27^{\text {th }}$ and $28^{\text {th }}$ October 2016. All the data collection and screening were carried out by a team of ten doctors and 6 research assistants. They were counseled and those identified to have CVD risk factors were referred for further evaluation.

Blood pressure (BP) was measured on the left arm with an accuson mercury sphygmomanometer, with the subjects relaxed and in sitting position. Hypertension was defined as BP $\geq 140 / 90 \mathrm{mmHg}$ according to JNC-7 criteria and also those presently taking antihypertensive therapy.

Obesity was screened by measuring the waist circumference (WC) at the midpoint between the subcostal margin and iliac crest with a measuring tape. Obesity was defined as WC of $94 \mathrm{~cm}$ for males and $80 \mathrm{~cm}$ for females according 
to National Cholesterol Education Program (NCEP) Expert Panel on Detection, Evaluation, and Treatment of High Blood Cholesterol in Adults (Adult Treatment Panel III) final report [13].

Accu-chek active glucometer was used to measure the blood glucose level. Diabetes mellitus was defined by either the presence of classical diabetes symptoms (polyuria, polydipsia, polyphagia) and random blood glucose of $\geq 200$ $\mathrm{mg} / \mathrm{dl}$ or people previously diagnosed to have diabetes mellitus and taking antidiabetic drugs [14].

Alcohol abuse was defined as use of alcoholic beverages of $>21$ units/week for males and $>14$ units/week for females. The number of units of alcohol in a drink was determined by multiplying the volume of the drink (in millilitres) by its percentage (Alcohol by volume), and dividing by 1000 [15].

Current smoker was defined as one that has smoked $>100$ cigarette in entire life and still smokes every day or some days [16].

Positive family history of stroke was defined by prior stroke in a first degree relative.

Data was analyzed with Statistical Package for the Social Sciences (SPSS) version 25. The categorical variables were arranged in proportions and percentages while numerical variables were presented as means and standard deviations. Chi-square was used to test for statistical significance and p-value of $<0.05$ as significant.

\section{Results}

A total of 1074 adults were seen with 567 males and 507 females (sex ratio of $\approx$ 1:1). The Age range was $18-80$ years with mean age of $35.63 \pm 12.45$ years. The details of age and sex distribution are shown in Table 1 . They were predominantly farmers 238 (22.1\%), petty traders 231 (21.5), artisan 190 (17.7), motor cyclist/driver 121 (11.2\%), civil servants 120 (11.1\%) and laborers 109 (10.2\%). The details are shown in Table 2.

The identified CVD risk factors were hypertension 285 (26.4\%), alcohol abuse 131 (12.1\%), obesity 122 (11.3\%), diabetes 97 (9\%), family history of stroke 87 (8.1\%), smoking $74(6.9 \%)$ and previous stroke $29(2.7 \%)$. The details are shown in Table 3 and Figure 1.

Table 1. Sex and age distribution.

\begin{tabular}{cccc}
\hline Age range & Male (\%) & Female (\%) & Total (\%) \\
\hline $18-20$ & $22(2.0)$ & $51(4.7)$ & $73(6.7)$ \\
$21-30$ & $156(14.5)$ & $149(13.8)$ & $305(28.3)$ \\
$31-40$ & $170(15.8)$ & $127(11.8)$ & $297(27.6)$ \\
$41-50$ & $123(11.4)$ & $94(8.7)$ & $217(20.1)$ \\
$51-60$ & $45(4.2)$ & $39(3.6)$ & $84(7.8)$ \\
$61-70$ & $27(2.5)$ & $32(3.0)$ & $59(5.5)$ \\
$71-80$ & $26(2.4)$ & $15(1.4)$ & $41(3.8)$ \\
Total & $569(52.9)$ & $507(47.1)$ & $1076(100)$
\end{tabular}


Table 2. Occupation distribution.

\begin{tabular}{cccc}
\hline Occupation & Male (\%) & Female (\%) & Total (\%) \\
\hline Farmers & $112(10.4)$ & $126(11.7)$ & $238(22.1)$ \\
Petty traders & $89(8.3)$ & $142(13.2)$ & $231(21.5)$ \\
Artisan & $106(9.9)$ & $84(7.8)$ & $190(17.7)$ \\
Motor cyclist/Driver & $121(11.2)$ & $0(0)$ & $121(11.2)$ \\
Civil servants & $68(6.3)$ & $52(4.8)$ & $120(11.1)$ \\
Laborers & $30(2.9)$ & $79(7.3)$ & $109(10.2)$ \\
Others & $43(4.0)$ & $24(2.2)$ & $67(6.2)$ \\
\hline
\end{tabular}

Table 3. CVD risk factors.

\begin{tabular}{ccccc}
\hline CVD Risk factor & Male (\%) & Female (\%) & Total (\%) & p \\
\hline Hypertension & $150(13.9)$ & $135(12.5)$ & $285(26.4)$ & $>0.05$ \\
Alcohol abuse & $122(11.3)$ & $9(0.8)$ & $131(12.1)$ & $<0.05$ \\
Obesity & $59(5.5)$ & $63(5.8)$ & $122(11.3)$ & $>0.05$ \\
Diabetes & $52(4.8)$ & $45(4.2)$ & $97(9.0)$ & $>0.05$ \\
Family history of stroke & $45(4.2)$ & $42(3.9)$ & $87(8.1)$ & $>0.05$ \\
Smoking & $70(6.5)$ & $4(0.4)$ & $74(6.9)$ & $<0.05$ \\
Previous stroke & $16(1.5)$ & $13(1.2)$ & $29(2.7)$ & $>0.05$ \\
\hline
\end{tabular}

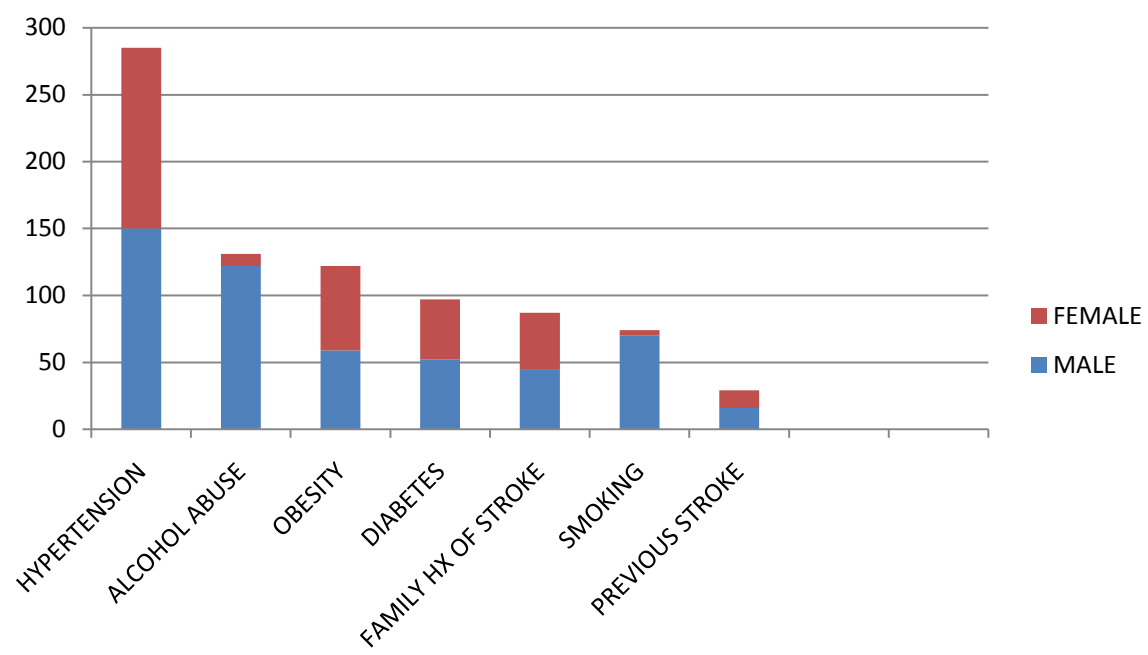

Figure 1. CVD risk factors.

\section{Discussion}

This is a community based study of prevalence of selected cardiovascular risk factors in a sub-urban community in Abakaliki south-eastern Nigeria. The identified risk factors were hypertension, alcohol abuse, obesity, diabetes mellitus, family history of stroke, smoking and previous history of stroke in descending order. 
The prevalence of hypertension was $26.4 \%$ with no sex predilection. This finding is similar with other community based studies in Nigeria and USA [8] [17] [18] [19]. It is lower than $42 \%$ reported amongst market workers in Enugu Nigeria with similar mean age [11]. The difference could stern from the fact that market workers were mainly sedentary while this study population was mainly active workers (farmers, laborers, artisans). The high prevalence of hypertension in this study underscores the high risk and enormous burden of cardiovascular diseases in sub-Saharan Africa.

Excessive use of alcoholic beverages was the second most prevalent cardiovascular risk factor identified with prevalence of $12.1 \%$ and male preponderance (11:1). The male preponderance is not unexpected as it's in keeping with multinational studies [20]. Men engage in significant alcohol use for several reasons which include cultural, social, biological, economic and religious reasons due to their low response to alcohol, later maturation in brain structures and executive function, greater estimates of perceived peer alcohol use, and socialization into traditional gender roles [21]. This contributes to high cardiovascular disease burden in male gender.

Obesity was reported in $11.3 \%$ of the study population with equal sex distribution. This is lower than prevalence rate of $27.3 \%$ reported in south-west Nigeria [22]. This difference is not unexpected as the former studied semi-urban dwellers mainly farmers and petty traders which were mostly of low socioeconomic class while the later studied health workers which are of higher socioeconomic class. Chukwuonye et al. reported prevalence of obesity in low and upper income groups of $12.2 \%$ and $20 \%$, respectively in south-eastern Nigeria [23]. The above shows that obesity is more prevalent in individuals of higher socioeconomic groups.

Diabetes was noted in $9 \%$ of the study population which is higher than $2.2 \%$ and $5.8 \%$ reported from nationwide survey of 1992 and a systematic review/ meta-analysis of 2018 in Nigeria respectively [24]. This shows steady rise in the prevalence of diabetes and typifies epidemiologic transition which is due to change to western lifestyle, dietary habits and urbanization.

History of stroke in first degree relative was noted in $8.1 \%$ while previous history of stroke was noted in $2.7 \%$ of the study population. Above figure is higher than previous systematic community based stroke prevalence of $1.5 \%$ in South-south part of Nigeria [25]. This high prevalence could stern from high prevalence of CVDs risk factors and also from chronic consumption of salty water in Ebonyi state [26].

Cigarette smoking was reported by $6.9 \%$ of the study population with male preponderance. This is not unexpected as majority of the study population were young and of low socioeconomic class which are both determinants for cigarette smoking [27]. This is higher than $0.8 \%$ cigarette smoking rate reported in southwest Nigeria [28]. This disparity could arise from the fact that the study population in former was young with mean age of 38 years compared to the mean age of 62 years in the later. 


\section{Conclusions and Recommendations}

This is a community based study of the cardiovascular risk factors. The identified CV risk factors were hypertension, alcohol abuse, obesity, diabetes, family history of stroke, smoking and previous history of stroke in descending order of frequency. They were quite prevalent with male preponderance of alcohol abuse and smoking.

There is need for a multicentre nationwide study to ascertain the actual burden of these risk factors in the larger population. There is need for a regular comprehensive community based education and enlightenment programs on healthy lifestyles and good health seeking behavior. There is also need to train adequate manpower in health sector who will be involved in provision of secondary and tertiary levels of care to the at-risk population. Finally, there is need for government to ensure provision of portable water for the populace.

\section{Conflicts of Interest}

The authors declare no conflicts of interest regarding the publication of this paper.

\section{References}

[1] Namara, K.M., Alzubaidi, H. and Jackson, J.K. (2019) Cardiovascular Disease as a Leading Cause of Death: How Are Pharmacists Getting Involved? Integrated Pharmacy Research and Practice, 8, 1-11. https://doi.org/10.2147/IPRP.S133088

[2] World Health Organization (2017) Cardiovascular Diseases (CVDs) Fact Sheet. http://www.who.int/news-room/fact-sheets/detail/cardiovascular-diseases-(cvds)

[3] Oguoma, V.M., Nwose, E.U., Skinner, T.C., Digban, K.A., Onyia, I.C. and Richards, R.S. (2015) Prevalence of Cardiovascular Disease Risk Factors among a Nigerian Adult Population: Relationship with Income Level and Accessibility to CVD Risks Screening. BMC Public Health, 15, 397. https://doi.org/10.1186/s12889-015-1709-2

[4] van de Vijver, S., Akinyi, H. and Oti, S. (2013) Status Report on Hypertension in Africa-Consultative Review for the 6th Session of the African Union Conference of Ministers of Health on NCD's. The Pan African Medical Journal, 16, 38-55. https://doi.org/10.11604/pamj.2013.16.38.3100

[5] World Health Organization (2016) Global Report on Diseases. World Health Organization, Geneva.

[6] Tibazarwa, K., Ntyintyane, L., Sliwa, K., et al. (2009) A Time Bomb of Cardiovascular Risk Factors in South Africa: Results from the Heart of Soweto Study "Heart Awareness Days". International Journal of Cardiology, 132, 233-239. https://doi.org/10.1016/j.ijcard.2007.11.067

[7] Hill, J.O., Peters, J.C., Catenacci, V.A. and Wyatt, H.R. (2008) International Strategies to Address Obesity. Obesity Reviews, 9, 41-47. https://doi.org/10.1111/j.1467-789X.2007.00437.x

[8] Daviglus, M.L., Talavera, G.A., Avilés-Santa, M.L., Allison, M., Cai, J., Criqui, M.H., Gellman, M., Giachello, A.L., Gouskova, N., Kaplan, R.C., LaVange, L., Penedo, F., Perreira, K., Pirzada, A., Schneiderman, N., Wassertheil-Smoller, S., Sorlie, P.D. and Stamler, J. (2012) Prevalence of Major Cardiovascular Risk Factors and Cardiovascular Diseases among Hispanic/Latino Individuals of Diverse Backgrounds in the 
United States. JAMA, 308, 1775-1784. https://doi.org/10.1001/jama.2012.14517

[9] Ogah, O.S., Madukwe, O.O., Onyeonoro, U.U., Chukwuonye, I.I., Ukegbu, A.U., Akhimien, M.O. and Okpechi, I.G. (2013) Cardiovascular Risk Factors and Non-Communicable Diseases in Abia State, Nigeria: Report of a Community-Based Survey. International Journal of Medicine and Biomedical Research, 2, 57-68. https://doi.org/10.14194/ijmbr.2110

[10] Dokunmu, T.M., Yakubu, O.F., Adebayo, A.H., Olasehinde, G.I. and Chinedu, S.N. (2018) Cardiovascular Risk Factors in a Suburban Community in Nigeria. International Journal of Hypertension, 2018, Article ID: 6898527. https://doi.org/10.1155/2018/6898527

[11] Ulasi, I.I., Ijoma, C.K., Onwubere, B.J., Arodiwe, E., Onodugo, O. and Okafor, C. (2011) High Prevalence and Low Awareness of Hypertension in a Market Population in Enugu, Nigeria. International Journal of Hypertension, 2011, Article ID: 869675. https://doi.org/10.4061/2011/869675

[12] Eze, C.O. and Kalu, U.A. (2019) Pattern of Mortality in Medical Emergency Room: Experience at Abakaliki Nigeria. Journal of Metabolic Syndrome, 8, 248.

[13] (2002) Third Report of the National Cholesterol Education Program (NCEP) Expert Panel on Detection, Evaluation, and Treatment of High Blood Cholesterol in Adults (Adult Treatment Panel III) Final Report. Circulation, 106, 3143-3421. https://doi.org/10.1161/circ.106.25.3143

[14] Odusan, O., Familoni, O.B. and Raimi, T.H. (2008) Correlates of Cardiac Autonomic Neuropathy in Nigerian Patients with Type 2 Diabetes Mellitus. The African Journal of Medical Sciences, 37, 315-320. https://doi.org/10.4314/nmp.v53i4.28929

[15] How Long Does Alcohol Stay in Your Blood? NHS.

[16] Ryan, H., Trosclair, A. and Gfroerer, J. (2012) Adult Current Smoking: Differences in Definitions and Prevalence Estimates-NHIS and NSDUH, 2008. Journal of Environmental and Public Health, 2012, Article ID: 918368. https://doi.org/10.1155/2012/918368

[17] Ugwuja, E.I., Ezenkwa, U.S., Nwibo, A.N., Ogbanshi, M., Idoko, O. and Nnabu, R. (2015) Prevalence and Determinants of Hypertension in an Agrarian Rural Community in Southeast Nigeria. Annals of Medical and Health Science Research, 5, 45-49. https://doi.org/10.4103/2141-9248.149787

[18] Ulasi, I.I., Ijoma, C.K. and Onodugo, O.D. (2010) A Community-Based Study of Hypertension and Cardio-Metabolic Syndrome in Semi-Urban and Rural Communities in Nigeria. BMC Health Services Research, 10, 71.

https://doi.org/10.1186/1472-6963-10-71

[19] Okubadejo, N.U., Ozoh, O.B., Ojo, O.O., Akinkugbe, A.O., Odeniyi, I.A., Adegoke, O., et al. (2019) Prevalence of Hypertension and Blood Pressure Profile amongst Urban-Dwelling Adults in Nigeria: A Comparative Analysis Based on Recent Guideline Recommendations. Clinical Hypertension, 25, 7. https://doi.org/10.1186/s40885-019-0112-1

[20] Wilsnack, R.W., Wilsnack, S.C., Kristjanson, A.F., Vogeltanz-Holm, N.D. and Gmel, G. (2009) Gender and Alcohol Consumption: Patterns from the Multinational GENACIS Project. Addiction, 104, 1487-1500. https://doi.org/10.1111/j.1360-0443.2009.02696.x

[21] Schulte, M.T., Ramo, D. and Brown, S.A. (2009) Gender Differences in Factors Influencing Alcohol Use and Drinking Progression among Adolescents. Clinical Psychology Review, 29, 535-547. https://doi.org/10.1016/j.cpr.2009.06.003 
[22] Iwuala, S.O., Ayankogbe, O.O., Olatona, F.A., Olamoyegun, M.A., OkparaIgwe, U., Sabir, A.A., et al. (2015) Obesity among Health Service Providers in Nigeria: Danger to Long Term Health Worker Retention? Pan African Medical Journal, 22, 1-8. https://doi.org/10.11604/pamj.2015.22.1.5586

[23] Chukwuonye, I.I., Chuku, A., Okpechi, I.G., Onyeonoro, U.U., Madukwe, O.O., Okafor, G.O. and Ogah, O.S. (2013) Socioeconomic Status and Obesity in Abia State, South East Nigeria. Diabetes, Metabolic Syndrome and Obesity, 6, 371-378. https://doi.org/10.2147/DMSO.S44426

[24] Uloko, A.E., Musa, B.M., Ramalan, M.A., Gezawa, I.D., Puepet, F.H., Uloko, A.T., Borodo, M.M. and Sada, K.B. (2018) Prevalence and Risk Factors for Diabetes Mellitus in Nigeria: A Systematic Review and Meta-Analysis. Diabetes Therapy, 9, 1307-1316. https://doi.org/10.1007/s13300-018-0441-1

[25] Ezejimofor, M.C., Uthman, O.A., Maduka, O., Ezeabasili, A.C., Onwuchekwa, A.C., Ezejimofor, B.C., et al. (2017) Stroke Survivors in Nigeria: A Door-to-Door Prevalence Survey from the Niger Delta Region. Journal of the Neurological Sciences, 372, 262-269. https://doi.org/10.1016/j.jns.2016.11.059

[26] Odikamnoro, O.O., Omowaye, O.S. and Aneke, G.U. (2014) The Quality and Composition of Borehole Water in Ebonyi State, Nigeria. Sci-Afric Journal of Scientific Issues, Research and Essays, 2, 15-18.

[27] Nketiah-Amponsah, E., Afful-Mensah, G. and Ampaw, S. (2018) Determinants of Cigarette Smoking and Smoking Intensity among Adult Males in Ghana. BMC Public Health, 18, 941. https://doi.org/10.1186/s12889-018-5872-0

[28] Oluyombo, R., Michael, A., Olamoyegun, M.A., Olaifa, O., Iwuala, S.O., Oluwole, A. and Babatunde, O.A. (2015) Cardiovascular Risk Factors in Semi-Urban Communities in Southwest Nigeria: Patterns and Prevalence. Journal of Epidemiology and Global Health, 5, 167-174. https://doi.org/10.1016/j.jegh.2014.07.002 